\title{
A Multiband Patch Antenna for WiMAX and S Band RADAR Applications
}

\author{
Allin Joe D, Umamaheswari S, Karthikumar R
}

\begin{abstract}
Microstrip patch antenna (MPA) have a valuable position in the communication commerce as it complete the dimension of antenna to shrivel and the outlay of the communication diplomacy is abridged due to its multiband possessions. The projected antenna intends is done by using Flame Retardant (FR4) substrate. The antenna is energized using a coaxial probe feed. The reproduction of the projected antenna intends is done by means of the High Frequency Structural Simulator (HFSS) software. The intended rectangular MPA has reverberating frequencies at $2.92 \mathrm{GHz}$, which is appropriate for S-Band Radio Detection and Ranging (RADAR), and at $3.45 \mathrm{GHz}$ which is appropriate for the applications that uses Worldwide Interoperability for Microwave Access (WiMAX) standard. The antenna intends that is proposed is uncomplicated and cost efficient.
\end{abstract}

Keywords- Microstrip Patch Antenna (MPA), Multiband, SBand RADAR, WiMAX, HFSS, Coaxial probe feed.

\section{INTRODUCTION}

Communication commerce increases an assortment of proceeds owing to the lessening in dimension of the communication components used in it. The substance used by the communication components wants to be extra cost efficient [1]. Therefore, Microstrip Patch Antenna (MPA) will turn into the appropriate constituent in a communication scheme owing to its uncomplicated configuration and cost efficient possessions [2]. Introducing multiband in MPA will diminish the dimension prerequisite of antenna as well as the communication system [3]. Assimilating the S-Band RADAR beside with the WiMAX standard will evade the need for the two devices for uncovering scheme and the third generation (3G) wireless communication system [4]. The intended rectangular MPA is energized at the underneath by means of the coaxial probe feed [5]. HFSS software is used for the scrutiny of the intended multiband MPA.

\section{PROPOSED ANTENNA DESIGN}

A multiband MPA is planned for S-Band RADAR and WiMAX purpose. A rectangular shaped patch antenna is intended based on the following equations (1-6) [6-8]. Let the effective dielectric invariable of the projected antenna that is planned be $\varepsilon_{r e}$ and is considered by means of the equation (1).

Revised Manuscript Received on 14 August, 2019.

Allin Joe D, Department of Electronics and Communication Engineering, Kumaraguru College of Technology, Coimbatore, Tamilnadu, India.

Umamaheswari S, Department of Electronics and Communication Engineering, Kumaraguru College of Technology, Coimbatore, Tamilnadu, India.

KarthikumarR , Department of Electronics and Communication Engineering, Kumaraguru College of Technology, Coimbatore, Tamilnadu, India..

$$
\varepsilon_{r e}=\frac{\varepsilon_{r}+1}{2}+\frac{\varepsilon_{r}-1}{2}\left[1+12 \frac{h}{W}\right]^{-\frac{1}{2}}
$$

The height or thickness of the substrate used for the antenna intends is indicated by $h, W$ indicate the width of the designed MPA and the dielectric invariable of the substrate be $\varepsilon_{r}$. The reverberation frequency of the rectangular MPA designed is characterized as $f_{0}$.For any $\mathrm{TM}_{\mathrm{mn}}$ mode, $\mathrm{m}$ and $\mathrm{n}$ are the modes of the intended rectangular MPA then the reverberating frequency is originate by equation (2) [9-10].

$$
f_{0}=\frac{C}{2 \sqrt{\varepsilon_{r e}}}\left[\left(\frac{\mathrm{m}}{\mathrm{L}}\right)^{2}+\left(\frac{\mathrm{n}}{\mathrm{W}}\right)^{2}\right]^{\frac{1}{2}}(2)
$$

The width (W) of the rectangular shaped patch antenna is measured by

$$
\mathrm{W}=\frac{C}{2 f_{0} \sqrt{\frac{\left(\varepsilon_{r}+1\right)}{2}}}
$$

The effectual span of the rectangular MPA $\left(L_{e f}\right)$ can be establish by

$$
\mathrm{L}_{\mathrm{ef}}=\mathrm{L}+2 \Delta \mathrm{L}
$$

where,

$$
\Delta L=0.412 \frac{\left(\varepsilon_{r e} \pm 0.3\right)\left(\frac{W}{h}+0.264\right)}{\left(\varepsilon_{r e}-0.3\right)\left(\frac{W}{h}+0.8\right)}
$$

The effectual length of the rectangular MPA $\left(\mathrm{L}_{\mathrm{ef}}\right)$ for any reverberation frequency $f_{0}$ is given by

$$
\mathrm{L}_{\mathrm{ef}}=\frac{C}{2 f_{0} \sqrt{\varepsilon_{r e}}}
$$

The projected rectangular MPA is intended over FR4 substrate and energized using a coaxial feed [11-12]. Figure 1 shows the top scrutiny of the rectangular MPA and Figure 2 shows the bottom scrutiny of the rectangular MPA.

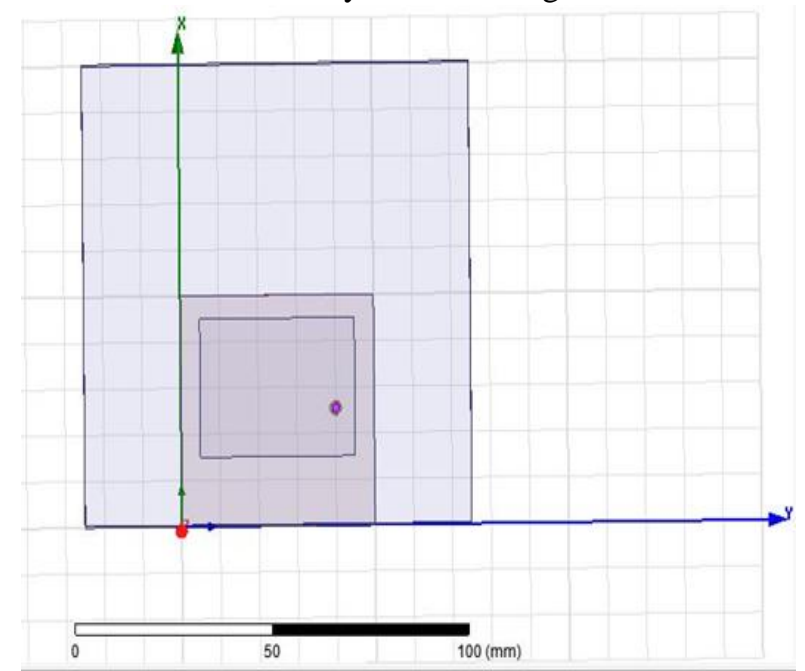

Fig. 1. Top side of MPA

Published By: 


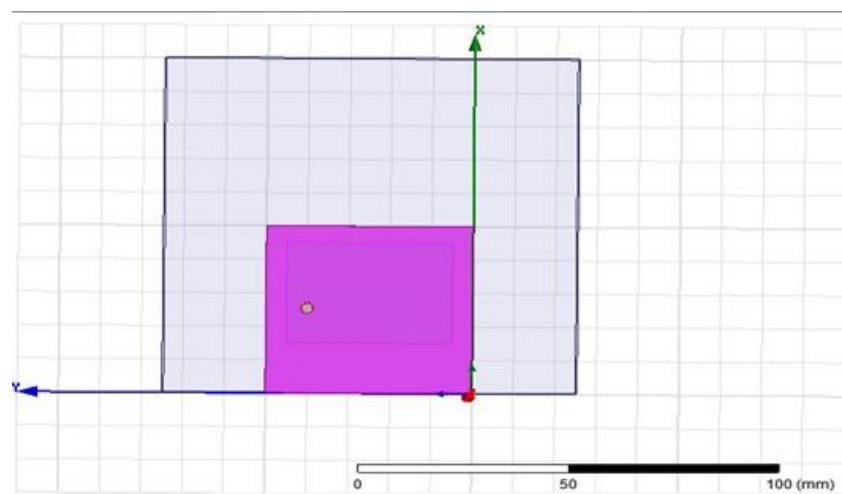

Fig. 2. Bottom side of MPA

\section{RESULTS AND DISCUSSION}

The rectangular MPA that is projected was intended based on the equations $(1-8)$ and the reproduction of the antenna is intended in HFSS software. The rectangular MPA was intended as per the proportions established from the plan equations and the coaxial probe feed was persuading over it. The coaxial probe feed is enthused all about the patch of the rectangular MPA and the most favorable site for the coaxial probe feed is establish which will produce the preferred multiband uniqueness. The return loss scheme of the rectangular MPA is exposed in Figure 3 and that has two reverberating frequencies. The return loss of the first reverberating frequency $2.92 \mathrm{GHz}$ as observe in Figure 3 is $17.9196 \mathrm{~dB}$, which is appropriate for the S-Band RADAR communication scheme principles. The return loss of the second reverberating frequency $3.45 \mathrm{GHz}$ as observe in Figure 3 is $-22.6681 \mathrm{~dB}$, which can activate the WiMAX standard functions.

The VSWR plan of the rectangular MPA is exposed in Figure 4. The VSWR ethics at $2.92 \mathrm{GHz}$ and $3.45 \mathrm{GHz}$ are appropriate for the S-Band RADAR and WiMAX functions. The emission prototype of the rectangular MPA at $2.92 \mathrm{GHz}$ reverberating frequency is shown in Figure 5. The emission prototype of the rectangular MPA at $3.45 \mathrm{GHz}$ reverberating frequency is exposed in Figure 5.

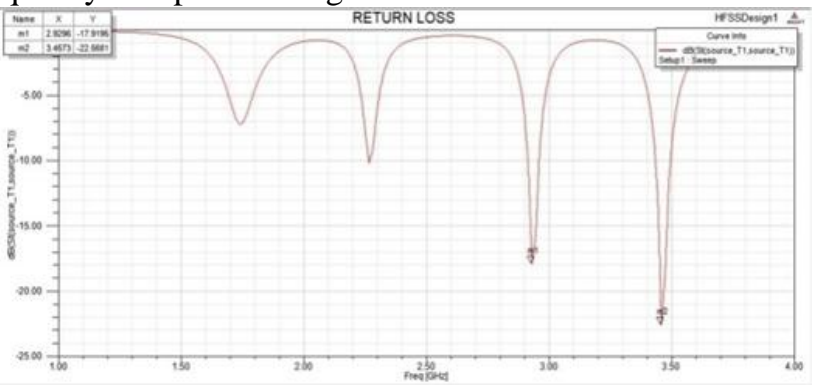

Fig. 3. Return Loss of MPA

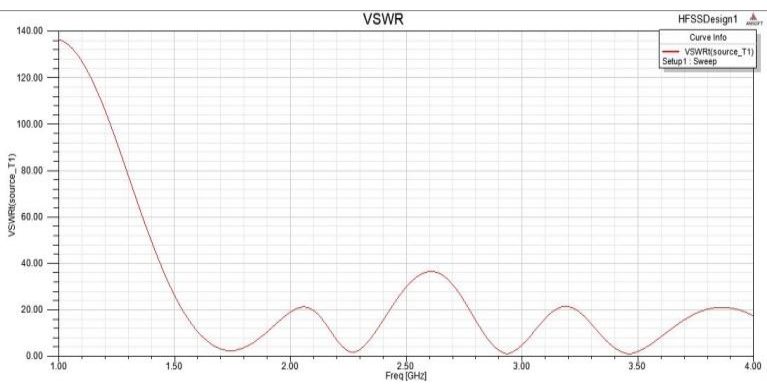

Fig. 4. VSWR of MPA

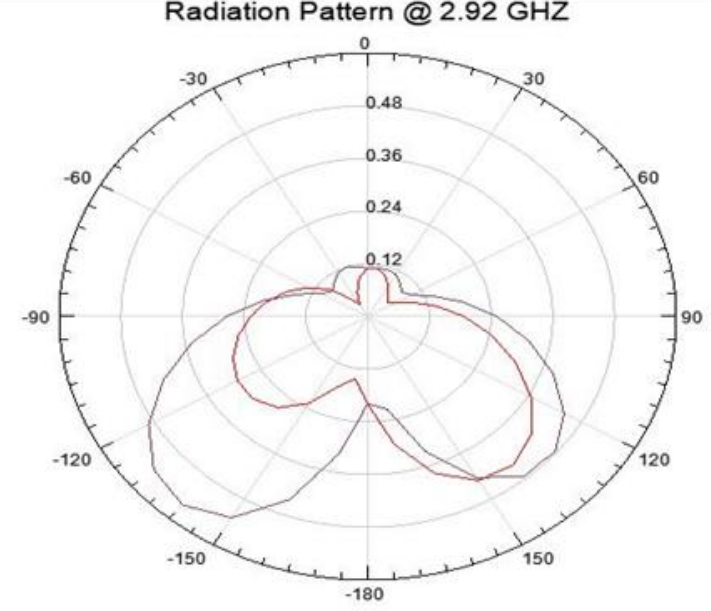

Fig. 5. Radiation pattern of MPA at $2.92 \mathrm{GHz}$

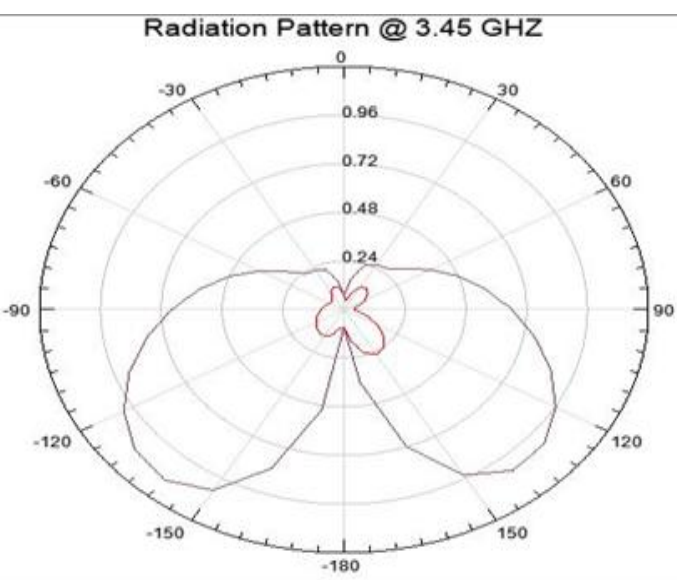

Fig. 6. Radiation pattern of MPA at $3.45 \mathrm{GHz}$

\section{CONCLUSION}

A multiband rectangular MPA for S-Band RADAR and WiMAX standard functions was intended and authenticated by means of the return loss plan and VSWR plan were produced by means of HFSS software. The intended antenna can maneuver in the preferred frequencies and can be more enhanced by means of Defective Microstrip Structures (DMS) and Defected Ground Structures (DGS).

\section{REFERENCES}

1. A. G. Koutinos, G. A. Ioannopoulos, M. T. Chryssomallis, and G. A. Kyriacou, "Bandwidth enhancement of rectangular patch antennas using multiple feeding points: A review," 7th International Conference on Modern Circuits and Systems Technologies (MOCAST), 2018.

2. P. R. Chopde and M. P. Joshi, "U-Slot Loaded Rectangular Microstrip Patch Antenna for Wideband Applications," International Conference On Advances in Communication and Computing Technology (ICACCT), 2018.

3. Allin Joe D, Pavithra, and Rajeshkumar V "A Compact Multiband Antenna for WLAN and WiMAX Applications using Minkowski Fractal and Defected Microstrip Structure", International Journal of Microwave and Optical Technology (IJMOT), vol.12, no.3, pp.198-203, May 2017. 
4. R. K. Bonde and B. R. Rathod, "Dual Band Circular Antenna for Wi-Fi and Radar Application," Second International Conference on Intelligent Computing and Control Systems (ICICCS), 2018.

5. K. Szostak and P. Slobodzian, "Broadband Dielectric Measurement of PCB and Substrate Materials by Means of a Microstrip Line of Adjustable Width," IEEE Microwave and Wireless Components Letters, vol. 28, no.10, pp. 945-947, 2018.

6. John D. Krauss, 1988. Antennas. McGraw Hill International.

7. Constantine A. Balanis, 1997. Antennas:Theory, Analysis and Design. John Wiley \& Sons, Inc.

8. Yi Huang and Kevin Boyle, 2008. Antennas from Theory to Practice. John Wiley \& Sons, Inc.

9. A. Priya and S. K. Mohideen, "Design Of Half Elliptic Circular Slot Monopole Antenna On A Partial Or Defected Rectangular Ground Plane For Wlan \& Uwb Applications," International Conference on Recent Trends in Electrical, Control and Communication (RTECC), 2018.

10. T. Bhandari and S. Baudha, "An UWB Compact Microstrip Antenna for S Band, C Band and X Band Applications," 12th European Conference on Antennas and Propagation (EuCAP 2018), 2018.

11. E. Sandi, R. Kurnia, and W. Djatmiko, "Design of Electromagnetic Band Gap to Improve Sidelobe Level for S-Band Antenna," International Conference on Radar, Antenna, Microwave, Electronics, and Telecommunications (ICRAMET), 2018

12. H. Naik, A. K. Awasthi, and A. R. Harish, "Sharedaperture dual-band orthogonally polarised antenna array for L-band and S-band applications," IET Microwaves, Antennas \& Propagation, vol. 13, no. 4, pp. 431-435, 2019. 